\title{
Palhada do sorgo de guiné gigante no estabelecimento de plantas daninhas em área de plantio direto
}

\author{
Gustavo Pavan Mateus ${ }^{(1)}$, Carlos Alexandre Costa Crusciol ${ }^{(2)}$ e Eduardo Negrisoli ${ }^{(1)}$
}

(1)Universidade Estadual Paulista (Unesp), Fac. de Ciências Agronômicas (FCA), Campos de Botucatu, Caixa Postal 237, CEP 18603-970 Botucatu, SP. E-mail: gmateus@fca.unesp.br (2)Unesp, FCA, Dep. de Produção Vegetal - Agricultura. E-mail: crusciol@fca.unesp.br

Resumo - A palhada na superfície do solo pode interferir na infestação de plantas daninhas das culturas de verão. O objetivo deste trabalho foi avaliar o efeito da quantidade de palhada do sorgo de guiné gigante sobre a população de plantas daninhas em área de plantio direto. $\mathrm{O}$ delineamento experimental foi de blocos ao acaso com quatro repetições. Os tratamentos constaram de 0, 6.100, 7.100, 19.500, 26.700, 28.100 e $30.200 \mathrm{~kg} \mathrm{ha}^{-1} \mathrm{de}$ palhada do sorgo de guiné sobre os quais foi realizada a semeadura de soja cultivar Monsoy-6101 na densidade de 25 sementes por metro e no espaçamento de $0,45 \mathrm{~m}$ entre linhas. Trinta dias após a semeadura, realizou-se o levantamento de plantas daninhas, em quatro amostras por parcela, por meio de moldura metálica de $1 \mathrm{~m}^{2}$. Houve redução significativa do número de plantas daninhas estabelecidas com o incremento da palhada. A partir de $15.000 \mathrm{~kg} \mathrm{ha}^{-1}$, o controle de plantas daninhas é superior a noventa por cento.

Termos para indexação: Sorghum bicolor, cobertura morta, semeadura direta.

\section{Gigantic guinea sorghum straw on the weed establishment in a no-tillage area}

Abstract - Crop residues on the surface of the soil can interfere in the infestation of weed of summer crops. The objective of this work was to evaluate the effect of the amount of Gigantic guinea sorghum straw on the population of weed established in a no-tillage area. The experimental design used was the randomized blocks, with four replications. The treatments consisted of zero, 6,100, 7,100, 19,500, 26,700, 28,100 and 30,200 $\mathrm{kg} \mathrm{ha}^{-1}$ of guinea sorghum straw. Soybean (cv. Monsoy-6101) was seeded over the treatments in a density of $25 \mathrm{seeds} \mathrm{m}^{-1}$ and $0.45 \mathrm{~m}$ between lines. Thirty days after the sowing of the culture, weed evaluation was accomplished. It consisted of four samplings per plot, through metallic frames of $1 \mathrm{~m}^{2}$. Significant reduction of the number of weeds was verified with the increment of the straw. The control of weeds is superior to ninety percent, from $15,000 \mathrm{~kg} \mathrm{ha}^{-1} \mathrm{on}$.

Index terms: Sorghum bicolor, cover crops, no-till.

\section{Introdução}

A manutenção de restos vegetais na superfície do solo em sistemas de produção agrícola com semeadura direta, além de proteger o solo da radiação solar, dissipa a energia de impacto das gotas de chuva, reduz a evaporação de água e aumenta a eficiência da ciclagem dos nutrientes (Gassen \& Gassen, 1996), consistindo ainda em uma alternativa de controle de plantas daninhas (Oliveira et al., 2001; Severino \& Christoffoleti, 2001).

A eliminação de plantas daninhas depende, entre outros fatores, do tipo e da quantidade da palha (Fiorin, 1999).

A cobertura vegetal reduz significativamente a intensidade de infestação de áreas por plantas daninhas e modifica a composição da população infestante (Almeida \& Rodrigues, 1985). A palha reduz a infestação de plan- tas daninhas por alterar a umidade, luminosidade e temperatura do solo, que são os principais elementos no controle da dormência e germinação de sementes (Pitelli, 1997; Theisen \& Vidal, 1999). A cobertura do solo pode atuar também como uma barreira física, impedindo a incidência de luz e a realização da fotossíntese por aqueles indivíduos que conseguiram emergir do solo (Fleck \& Vidal, 1993; Azania et al., 2002).

Os resíduos vegetais interferem na sobrevivência do banco de sementes por favorecerem a ocorrência de predadores como insetos, moluscos e crustáceos (Kremer \& Spencer, 1989), que danificam fisicamente as sementes, afetando sua viabilidade (Vidal \& Theisen, 1999). Além disso, a palhada cria condições para instalação de uma densa microbiocenose na camada superficial do solo, e há uma grande quantidade desses orga- 
nismos que pode utilizar sementes e plântulas de ervas daninhas como fontes de energia (Pitelli, 1997), provocando a deterioração e a perda da viabilidade de sementes no solo (Vidal \& Theisen, 1999).

A palhada pode atuar, ainda, por efeitos químicos, por meio de alterações na relação $\mathrm{C} / \mathrm{N}$ do solo e pela ação alelopática (Favero et al., 2001), que impedem ou diminuem a germinação e o desenvolvimento das plantas daninhas. Os compostos químicos responsáveis pela alelopatia são denominados aleloquímicos e cada espécie pode produzir um conjunto diferente de aleloquímicos com ação diferenciada sobre os componentes da comunidade em que está inserida (Putnam et al., 1983), dependendo, principalmente, da quantidade do materia vegetal depositado na superfície, do tipo de solo, da população microbiana e das condições climáticas (Pitelli, 1997).

Portanto, associada aos aspectos conservacionistas, a presença da palha na superfície do solo pode reduzir a densidade da população de plantas daninhas, e em culturas de verão, como soja, feijão e milho, semeadas no sistema de plantio direto sobre coberturas mortas densas, de lenta decomposição e com ação alelopática, pode reduzir ou até mesmo dispensar o uso de herbicidas (Oliveira et al., 2001).

O sorgo é uma excelente alternativa como cultura de cobertura de inverno no estabelecimento do sistema de semeadura direta, por causa da sua resistência às condições de déficit hídrico, com elevada capacidade de aproveitamento da água e conversão em fitomassa seca (Magalhães et al., 2000).

O sorgo de guiné pool vermelho (Sorghum bicolor subespécie bicolor raça guinea), denominado sorgo de guiné gigante, vem se destacando como espécie promissora em sistema de rotação de culturas, em regiões de inverno seco. Segundo Mateus (2003), essa espécie produz altos níveis de matéria seca mesmo sob condições climáticas desfavoráveis para a maioria das culturas. Assim, esse genótipo pode vir a ser cultivado com o propósito de produzir palhada para o sistema de semeadura direta, proporcionando melhoria nas características físicas, químicas e biológicas do solo, bem como contribuindo para redução das plantas daninhas permitindo uma diminuição gradativa do banco de sementes ao longo dos anos e reduzindo custos com herbicidas.

O objetivo deste trabalho foi avaliar o efeito da quantidade de palhada de sorgo de guiné gigante sobre a população de plantas daninhas em área de plantio direto.

\section{Material e Métodos}

O trabalho foi desenvolvido no ano agrícola de 2001/2002, na Fazenda Experimental Lageado da Uni- versidade Estadual Paulista, em Botucatu, SP, em um Nitossolo Vermelho estruturado (Embrapa, 1999). $\mathrm{O}$ delineamento experimental utilizado foi o de blocos ao acaso, com sete tratamentos e quatro repetições. Os tratamentos constituíram-se de 0, 6.100, 7.100, 19.500, $26.700,28.100$ e $30.200 \mathrm{~kg} \mathrm{ha}^{-1}$ de palha de sorgo de guiné gigante. Esses valores foram obtidos em experimento de épocas de semeadura com sorgo de guiné gigante (Sorghum bicolor subs. bicolor raça guinea) em sistema de plantio direto, com registro de sensibilidade ao fotoperíodo dessa espécie, florescendo em uma única data, independentemente da época de semeadura, formando assim um gradiente de palhada.

Os níveis de palhada foram obtidos com o auxílio de uma moldura metálica de $1 \mathrm{~m}^{2}$, e consistiram de médias de quatro amostragens aleatórias por parcela. $\mathrm{O}$ material coletado foi secado em estufa de circulação forçada de ar a $60^{\circ} \mathrm{C}$; em seguida, foi pesado e os dados transformados em $\mathrm{kg} \mathrm{ha}^{-1}$, sendo que no tratamento sem palha não se cultivou sorgo anteriormente. Cada parcela foi constituída por 10 linhas de soja de 20 m de comprimento, espaçadas em 0,45 m. Nas avaliações, foram consideradas as oito linhas centrais, sendo que $0,5 \mathrm{~m}$ da extremidade de cada linha e as duas linhas externas constituíram-se na bordadura, perfazendo uma área útil de $68,40 \mathrm{~m}^{2}$.

Em outubro de 2001, realizou-se a trituração das plantas de sorgo, deixando a fitomassa na superfície do solo, que constituiu as parcelas. A dessecação das plantas daninhas foi realizada com aplicação de $1.920 \mathrm{~g}$ de i.a. ha ${ }^{-1}$ de glyphosate antes da semeadura da soja.

A cultivar de soja Monsoy-6101 foi semeada no dia 6 de novembro de 2001, por meio de semeadora de plantio direto na densidade de aproximadamente 450.000 sementes $\mathrm{ha}^{-1}$, e a adubação de semeadura constou da aplicação de $300 \mathrm{~kg} \mathrm{ha}^{-1}$ do fertilizante formulado 8-28-16.

Trinta dias após a semeadura, realizou-se o levantamento das plantas daninhas, por espécie, que consistiu em quatro amostragens aleatórias por parcela, utilizando-se a moldura metálica de $1 \mathrm{~m}^{2}$. Com as médias, determinou-se a densidade de plantas em função da palhada do sorgo de guiné, ajustando-se as curvas de regressão e escolhendo-se o modelo significativo de melhor ajuste. Estimou-se também o controle de plantas daninhas em função dos níveis de palhada. A fórmula utilizada no cálculo de controle foi: $\mathrm{C}=[1-(\mathrm{I} / 100)]$, em que $\mathrm{C}$ é o controle de plantas daninhas, em \%; I é a incidência de plantas daninhas (no de plantas daninhas observadas/no de plantas daninhas total), em $\%$. 


\section{Resultados e Discussão}

As principais plantas daninhas na área experimental foram: o capim-braquiária (Brachiaria decumbens), o capim-marmelada (Brachiaria plantaginea), a guanxuma (Sida rhombifolia), a malva (Sida cordifolia), a nabiça (Raphanus raphanistrum), o picão-branco (Galinsoga ciliata), o picão-preto (Bidens pilosa) e o trevo (Oxalis latifolia). As folhas largas foram as principais infestantes e o trevo e a nabiça foram as espécies predominantes. Após o levantamento florístico, os números de plantas de cada espécie foram agrupados em duas classes: gramíneas e folhas largas. Os elevados valores de $\mathrm{R}^{2}$ comprovam a adequação dos métodos empregados (Tabela 1 ).

O número de plantas daninhas, de todas as espécies, diminuiu de forma exponencial com o incremento do nível de palhada (Figura 1). Theisen \& Vidal (1999) e Theisen et al. (2000) verificaram redução significativa da incidência de plantas daninhas com incremento de palhada de aveia na superfície do solo. A redução constatada pode estar relacionada a fatores físicos, tais como a palhada, que impede a penetração da radiação solar (Fener, 1980), diminuindo a amplitude térmica e hídrica do solo (Bragagnolo \& Mielnickzuk, 1990), e que atua como barreira física ao crescimento normal das plântulas (Theisen et al., 2000; Azania et al., 2002). Fatores químicos, como substâncias alelopáticas liberadas pelos resíduos vegetais (Putnam et al., 1983), e as mudanças na relação $\mathrm{C} / \mathrm{N}$ e nos níveis de nitrato no solo também podem ter contribuído para a redução. Outros fatores seriam os biológicos, como insetos e patógenos encontrados na camada de palhada (Kremer \& Spencer, 1989).

Tabela 1. Parâmetros e coeficientes dos modelos matemáticos de regressão utilizados nas análises dos dados experimentais $^{(1)}$.

\begin{tabular}{|c|c|c|c|c|c|}
\hline \multirow{2}{*}{ Variável } & \multicolumn{5}{|c|}{ Parâmetro } \\
\hline & $\mathrm{a}$ & $\mathrm{b}$ & $\mathrm{c}$ & $\mathrm{F}$ & $\mathrm{R}^{2}$ \\
\hline & \multicolumn{5}{|c|}{ Densidade de plantas $\left(\mathrm{n}^{\mathrm{o}}\right) \mathrm{y}=\mathrm{a}^{*} \exp \left(-\mathrm{b}^{*} \mathrm{x}\right)$} \\
\hline amíneas & 30,227 & $2,6660 \mathrm{e}^{-4}$ & - & $1.183^{* *}$ & 0,9785 \\
\hline Folhas largas & 225,120 & $1,7331 \mathrm{e}^{-4}$ & - & $1.805^{* *}$ & 0,9858 \\
\hline otal & 255,375 & $1,8181 \mathrm{e}^{-4}$ & - & $1.710 * *$ & 0,9850 \\
\hline & \multicolumn{5}{|c|}{ Controle de plantas $(\%)$ y $=a^{*}\left(1-10^{-c(x+b)}\right)$} \\
\hline ami & 97,67 & & & $33.931 * *$ & 0,9647 \\
\hline olhas largas & 96,82 & $-439,26$ & 0,0000781 & $67.911 * *$ & 0,9852 \\
\hline otal & 96,75 & $-446,04$ & 0,0000816 & $63.077 * *$ & 0,9836 \\
\hline
\end{tabular}

(1) Na equação, x representa a palhada de sorgo de guiné $\left(\mathrm{kg} \mathrm{ha}^{-1}\right)$. **Significativo a $1 \%$ de probabilidade, pelo teste de Tukey.
Em todos os níveis de palhada, as folhas largas estiveram em número maior em relação às gramíneas ( $\mathrm{Fi}-$ gura 1), o que pode ser atribuído ao menor banco de sementes de gramíneas na área experimental. Mesmo no tratamento sem palha, o número de gramíneas foi muito inferior ao das folhas largas. Assim, a curva de densidade total de plantas foi semelhante à de folhas largas.

$\mathrm{O}$ aporte de $5 \mathrm{t} \mathrm{ha}^{-1}$ de palhada proporcionou um controle de 66, 54 e 56\% nas gramíneas, folhas largas e no total de plantas, respectivamente (Figura 1). Já o aporte de $15 \mathrm{t} \mathrm{ha}^{-1}$ de palhada controlou em 95,90 e $90 \%$ a incidência de gramíneas, folhas largas e total de plantas, respectivamente, quando comparados à ausência de palhada. Esses resultados revelam o efeito da palhada do sorgo na inibição do crescimento e no desenvolvimento das plantas daninhas. Resultados mais pronunciados foram constatados por Theisen \& Vidal (1999), ou seja, redução da população de Brachiaria plantaginea em mais de $95 \%$, proporcionada por 5,2 tha ${ }^{-1}$ de palhada, em relação ao solo desnudo. Teasdale et al. (1991) também obtiveram redução de até $78 \%$ no número de plantas daninhas com cobertura de palha superior a $3 \mathrm{tha}^{-1}$.

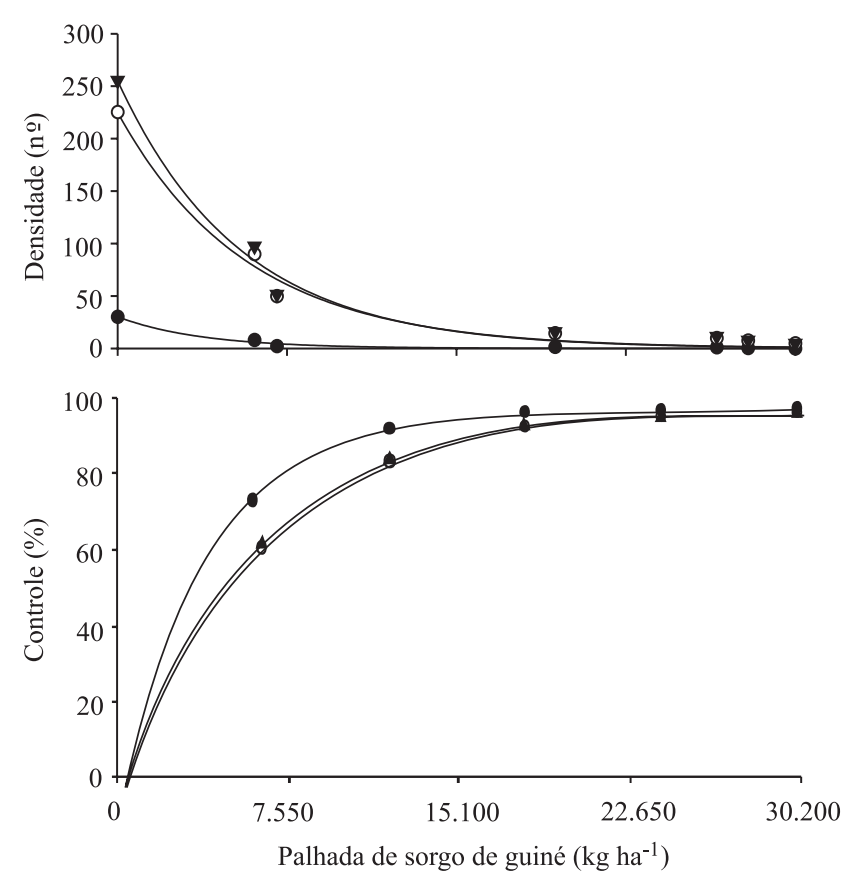

Figura 1. Densidade e controle de plantas daninhas (gramíneas, •; folhas largas, o; total, v ) na cultura da soja, aos 30 dias após a semeadura, em função da quantidade de palhada de sorgo de guiné. 
Assim, a manutenção de grande quantidade de palhada na superfície do solo pode proporcionar maior conservação do solo, melhoria da sua fertilidade (Gassen \& Gassen, 1996), aumento da população da micro e mesofauna (Kremer \& Spencer, 1989) e redução da população de plantas daninhas (Theisen \& Vidal, 1999; Theisen et al., 2000).

Independentemente das diferenças observadas entre as espécies, há uma tendência similar de comportamento e a taxa de redução das plantas daninhas decresce progressivamente com o incremento de palhada, tendendo a uma estabilização a partir de $10 \mathrm{t} \mathrm{ha}^{-1}$ (Figura 1).

\section{Conclusão}

A palhada na superfície do solo diminui a infestação de plantas daninhas na cultura da soja em plantio direto.

\section{Agradecimento}

Ao conselho Nacional de Desenvolvimento Científico e Tecnógico pela bolsa concedida ao autor Carlos Alexandre Costa Crusciol.

\section{Referências}

ALMEIDA, F.S.; RODRIGUES, N.B. Plantio direto. In: Guia de herbicidas: contribuição para o uso adequado em plantio direto e convencional. Londrina: Iapar, 1985. p.341-399.

AZANIA, A.A.P.M.; AZANIA, C.A.M.; GRAVENA, R.; PAVANI M.C.M.D.; PITELLI, R.A. Interferência da palha de cana-de-açúcar (Saccharum spp.) na emergência de espécies de plantas daninhas da família Convolvulaceae. Planta Daninha, v.20, p.207-212, 2002. BRAGAGNOLO, N.; MIELNICKZUK, J. Cobertura do solo por palha de trigo e seu relacionamento com a temperatura e umidade do solo. Revista Brasileira de Ciência do Solo, v.14, p.369-374, 1990.

EMBRAPA. Centro Nacional de Pesquisa de Solos (Rio de Janeiro, RJ). Sistema brasileiro de classificacão de solos. Brasília: Embrapa-SPI; Embrapa-CNPS, 1999. 412p.

FAVERO, C.; JUCKSCH, I.; ALVARENGA, R.C.; COSTA, L.M. Modificações na população de plantas espontâneas na presença de adubos verdes. Pesquisa Agropecuária Brasileira, v.36, p.13551362, 2001.
FENER, R. Germination tests of thirty-two East African weed species. Weed Research, v.20, p.135-138, 1980.

FIORIN, J.E. Plantas recuperadoras da fertilidade do solo. In: FERTILIDADE do solo em plantio direto: resumos de palestras. Cruz Alta: Revista Plantio Direto, 1999. p.39-55. Curso sobre aspectos básicos de fertilidade do solo sob plantio direto.

FLECK, N.G.; VIDAL, R.A. Efeitos de métodos físicos de controle de plantas daninhas sobre características agronômicas do girassol. Pesquisa Agropecuária Brasileira, v.28, p.1307-1318, 1993

GASSEN, D.N.; GASSEN, F.R. Plantio direto. Passo Fundo: Aldeia Sul, 1996. 207p.

KREMER, R.J.; SPENCER, N.R. Impact of a seed-feeding insect and microorganisms on velvetleaf (Abutilon theophrasti) seed viability. Weed Science, v.37, p.211-216, 1989.

MAGALHÃES, P.C.; DURAES, F.O.M.; SCHAFFERT, R.E. Fisiologia da planta de sorgo. Sete Lagoas: Embrapa-CNPMS, 2000. 46p. (Circular Técnica, 3).

MATEUS, G.P. Utilização agropecuária do sorgo de guiné e efeitos na cultura da soja e nos atributos químicos do solo. 2003. 142p. Dissertação (Mestrado) - Universidade Estadual Paulista, Botucatu.

OLIVEIRA, M.R.; ALVARENGA, R.C.; OLIVEIRA, A.C.; CRUZ J.C. Efeito da palha e da mistura atrazine e metolachlor no controle de plantas daninhas na cultura do milho, em sistema de plantio direto. Pesquisa Agropecuária Brasileira, v.36, p.37-41, 2001.

PITELLI, R.A. Dinâmica de plantas daninhas no sistema de plantio direto. In: SIMPÓSIO SOBRE HERBICIDAS E PLANTAS DANINHAS, 1997, Dourados. Resumos. Dourados: EmbrapaCPAO, 1997. p.50-61.

PUTNAM, A.R.; DEFRANK, J.; BARNES, J.P. Explotation of allelopathy for weed control in annual and perennial cropping systems. Journal of Chemical Ecology, v.9, p.1001-1010, 1983. SEVERINO, F.J.; CHRISTOFFOLETI, P.J. Efeitos de quantidades de fitomassa de adubos verdes na supressão de plantas daninhas. Planta Daninha, v.19, p.223-228, 2001

TEASDALE, J.R.; BESTE, C.E.; POTTS, W.E. Response of weeds to tillage and cover crop residue. Weed Research, v.39, p.195-199, 1991

THEISEN, G.; VIDAL, R.A. Efeito da cobertura do solo com resíduos de aveia-preta nas etapas do ciclo de vida do capim marmelada. Planta Daninha, v.17, p.189-196, 1999

THEISEN, G.; VIDAL, R.A.; FLECK, N.G. Redução da infestação de Brachiaria plantaginea em soja pela cobertura do solo com palha de aveia preta. Pesquisa Agropecuária Brasileira, v.35, p.753756,2000

VIDAL, R.A.; THEISEN, G. Efeito da cobertura do solo sobre a mortalidade de sementes de capim-marmelada em duas profundidades no solo. Planta Daninha, v.17, p.339-344, 1999. 